\title{
H umanização e cuidado: a experiência da equipe de um serviço de DST/Aids no município de São Paulo
}

\author{
H umanization and care: the experience \\ of an STD/Aids healthcare team \\ in the city of São Paulo
}

\begin{abstract}
Luzia A parecida Oliveira 1
M aria Ângela Silva Landroni 1

N eide Emy Kurokawa e Silva 1

José Ricardo de C. M. Ayres 2
\end{abstract}

\footnotetext{
1 Serviço de Assistência Especializada em DST/Aids M arcos Lotenberg, Santana, Secretaria M unicipal de Saúde de São Paulo. Rua Luís Lustosa da Silva 339, M andaqui, 024060-040, São Paulo SP. neks@uol.com.br

2 Departamento de M edicina Preventiva da Faculdade de M edicina da Universidade de São Paulo.
}

A bstract The Brazilian debate on humanization has stressed the relevance of a comprehensive approach to health. This approach requires that professionals revisit their attitudes and conceptions, straightly oriented in a biomedical sense. This reflexive essay examines a discussion process conducted by a multidisciplinary team of an HIV/Aids ambulatory in the city of São Paulo, with a view to the relationship between care and humanization of health practices. It was identified that the team considered that care provided by them was "humanized", once diverse patients needs, beyond those strictly related to the clinical control of HIV infection, were actively considered and responded to. Objections were made nonetheless, that those needs were not effectively incorporated into health care process, remaining just as obstacles to the adherence of patients to the therapeutic prescriptions, and informally responded to by means of staff personal initiatives and compassionate feelings. The discussion highlights the relevance of affectionate dimension in the encounters of health professional and services users, concluding by the importance of understanding humanization of health assistance as a dialogue process between technical aspects of health work and the users' life projects.

Key words H umanization of health assistance, Care, HIV/Aids, Compassion, Dialogue
Resumo 0 debate brasileiro sobre humanização da atenção à saúde tem valorizado uma abordagem integral da saúde. Tal orientação requer que os profissionais revejam suas atitudes e concepções, excessivamente centradas em um enfoque biomédico. Este ensaio é uma reflexão sobre um processo de discussão em torno do trabalho da equipe multiprofissional de um ambulatório especializado em HIV/Aids na cidade de São Paulo, tendo por norte as relações entre cuidado ehumanização das ações de saúde. I dentificou-se que a equipe considerava humanizada a atenção prestada, por haver escuta e resposta a diferentes necessidades dos usuários, além do controle da infecção pelo HIV. Levantou-se, entretanto, que tais necessidades não chegavam a ser incorporadas ao projeto de atenção propriamente dito, mas eram tomadas apenas na condição de obstáculos à adesão às medidas terapêuticas prescritas, recebendo, muitas vezes, respostas de caráter informal, dependentes de iniciativas de cunho pessoal, e motivadas por sentimentos compassivos. Ressalta-se a relevância da dimensão afetiva no encontro entre profissionais e usuários, concluindo-se pela importância de entender a humanização da atenção à saúde como um processo de diálogo, que garanta e estimule uma crescente integração entre as finalidades técnicas do trabalho e os projetos de vida dos usuários.

Palavras-chave Humanização da atenção à saúde, Cuidado, HIV/Aids, Compaixão, Diálogo 


\section{H umanização e a atenção às pessoas com HIV/Aids}

Sob o ideal de "humanização da atenção à saúde", observam-se diferentes iniciativas no Brasil, tanto na forma de uma política nacional (H umanizaSus), como de propostas técnicas mais específicas (H umanização do Parto; $M$ aternidade Segura; M étodo Canguru). Sem desconsiderar a centralidade do acesso à atenção à saúde e a qualidade técnica das ações desenvolvidas, as propostas de humanização têm dado especial ênfase à integralidade da atenção e, em particular, às interações entre profissionais e usuários nos serviços de saúde (M inistério da Saúde, 2005).

Deslandes (2004), examinando documentos oficiais sobre a humanização da atenção hospitalar, aponta que o conceito de humanização da atenção conforma-se como uma diretriz de trabalho, que aspira a uma nova " práxis" para a atenção à saúde. Tal inovação, de caráter processual e complexo, prevê mudanças que podem gerar insegurança e resistências por parte dos profissionais de saúde, já que não são passíveis de padronizações nem são generalizáveis, enfatizando a singularidade dos processos de aten ção à saúde, como corrobora M artins (2003).

A superação das dificuldades de interação entre profissionais e usuários de serviços de saúde, reclamadas pelas propostas de humanização, não é entendida, nesse sentido, como um desafio exclusivamente técnico. Deslandes (2004) aponta a natureza social desse desafio, destacando a importância de aspectos tais como a cultura organizacional e recursos para uma mudança na mesma, as relações assimétricas entre profissional-usuário e a hegemonia de uma objetividade científica utilitarista.

Quando se examina a questão da humanização no campo particular da atenção à saúde das pessoas vivendo com HIV/Aids, observa-se uma condição privilegiada, especialmente quando comparada à rede de saúde pública como um todo, tanto na oferta de insumos para o tratamento, quanto nos chamados "fatores humanos" da atenção (Nemes, 2001).

Nemes et al. (1999), tomando por base seu estudo sobre a adesão dos usuários ao tratamento anti-retroviral, ressaltam vantagens da qualidade do cuidado aos portadores de HIV/ Aids sobre outros serviços do sistema público de saúde brasileiro, como: quantidade e capacitação técnica da equipe, suprimento de medi- camentos, acesso a exames específicos, desempenho da equipe e satisfação do usuário.

Do ponto de vista do tratamento, além do acesso a medicamentos específicos, a atenção à saúde das pessoas vivendo com HIV/Aids conta ainda com os Consensos de Terapia (M inistério da Saúde, 2004a; 2004b; 2004c), que visam facilitar o manejo da doença, fornecendo orientações que vão desde a profilaxia da infecção pelo HIV em gestantes e bebês até a escolha dos esquemas terapêuticos medicamentosos para adultos, garantindo um padrão mínimo de qualidade técnica no conjunto dos serviços.

Quanto aos aspectos interacionais e "humanos" da atenção, contudo, identificam-se ainda muitos desafios para a construção de uma nova práxis também nos serviços de DST/Aids, sobretudo quando se tem por horizonte um novo modelo, uma nova cultura de atendimento. Visando apontar esta lacuna e contribuir para sua compreensão e superação, o presente artigo tem como objetivo refletir sobre a questão da humanização da atenção à saúde no cotidiano do trabalho de um serviço ambulatorial de atenção a pessoas vivendo com HIV/Aids na cidade de São Paulo, o SAE M arcos Lotenberg, da Secretaria M unicipal de Saúde de São Paulo (SAE-Santana), de cuja equipe são membros parte dos autores.

Com esse propósito, examinaremos um processo de discussão conduzido nessa unidade acerca do trabalho aí desenvolvido, tendo como horizonte as propostas de humanização em debate no Brasil, especialmente 0 aspecto das interações profissional-usuário. Vale esclarecer que tal processo, não concebido originalmente como um trabalho de pesquisa, foi desencadeado como uma atividade de gestão e supervisão originada da necessidade da equipe de discutir dificuldades de seu cotidiano. No entanto, a riqueza da experiência, a íntima relação dos conteúdos emergidos e trabal hados com as recentes discussões sobre humanização da atenção à saúde e, por fim, a produção ainda relativamente escassa acerca da humanização no contexto específico da atenção às pessoas vivendo com HIV/Aids, levou-nos a produzir este artigo. Não se trata, portanto, de um relato sistemático dos achados de uma investigação empírica, mas de um ensaio reflexivo com base em uma experiência do serviço.

A pesar de o estudo da experiência ter sido definido após seu desenvolvimento, o conteúdo aqui apresentado aproxima-se, em seu modo de produção, de uma observação partici- 
pante, uma vez que os autores foram parte ativa do processo que estudam. 0 tratamento da experiência foi de natureza hermenêutica ( $\mathrm{Ga}$ damer, 1997), tendo por substrato das interpretações realizadas as impressões colhidas na participação direta nas atividades de discussão, assim como os relatos de discussão de subgrupos. 0 quadro teórico que orientou tanto a proposição da atividade no serviço como sua reapropriação crítica na presente reflexão tem como referência central a discussão do Cuidado, tal como elaborada por Ayres (2001; 2004a; 2004b).

Para o desenvolvimento do ensaio, procuraremos, num primeiro momento, apresentar em suas linhas gerais o quadro teórico de referência. A seguir serão apresentados sumariamente e examinados criticamente o processo de discussão conduzido na equipe, em seus principais conteúdos. Para concluir, serão apontados aportes teórico-filosóficos que nos pareceram enriquecer a reflexão acerca dos caminhos para a humanização dos serviços de saúde de modo geral.

\section{Técnica e humanização das práticas de saúde}

Em um estudo sobre o trabalho do médico, Schraiber (1997) destaca e analisa a clássica divisão que distingue um componente científicotecnológico e um componente humanístico na prática da medicina. A autora aponta que essa separação tem implicado uma hierarquização, segundo a qual o aspecto científico-tecnológico ocupa um papel preponderante sobre o humanístico, tanto do ponto de vista dos próprios profissionais de saúde quanto da sociedade de modo geral.

Embora essa medicina científico-tecnológica tenda a afirmar-se como modelo hegemônico, Schraiber (1997) alerta também para o caráter interativo das práticas de saúde e para a particularidade de cada caso clínico, o que conforma uma dimensão da atenção à saúde que não pode ser intei ramente controlada e resolvida como estrita aplicação técnica de um saber de natureza científica. Essa discussão que Schraiber faz com relação à profissão médica é perfeitamente ampliável para além dela, de tal modo que podemos apontar um conjunto de contradições próprias à "racionalidade biomédica" em geral (Camargo Júnior, 1994) perpassando todas as profissões de saúde.
A dimensão biomédica da atenção à saúde Ihe imprime, necessariamente, um critério normativo de êxito que reside, fundamentalmente, no controle de riscos, na correção de uma disfunção ou dismorfia ou no restabelecimento de um bem-estar físico ou psíquico. Sua inexorável dimensão não-técnica, contudo, implica que qualquer proposta de êxito técnico dependerá sempre de um "sucesso prático" (Ayres, 2001), isto é, da capacidade desta intervenção de atender, para além dos sentidos normativos acima listados, às aspirações cotidianas dos usuários dos serviços, relacionadas à saúde, mas também e especial mente à vida de forma mais ampla, ao bem viver de modo geral (Ayres, 2004a). São essas aspirações mais amplas ao bem viver que chamamos de "projetos de felicidade", e os modos como estes são construídos, obstaculizados e reconstruídos ajudam a compreender não apenas a gênese dos processos de adoecimento e sofrimento que os usuários e as comunidades apresentam para os serviços de saúde, mas também o modo como são geridos e manejados no cotidiano (Ayres, 2004b).

Em outros termos, cada usuário de um serviço de saúde constituirá sempre um "caso" a ser apreciado em dois sentidos diversos, embora interligados. Será um caso no sentido de aplicação de determinadas regras ou comportamentos universal mente verificáveis à situação particular do indivíduo doente, caracterizando sua condição clínica particular (seu caso de saúde), conforme categorias utilizadas pela medicina, enfermagem, psicologia, fonoaudiologia, terapia ocupacional, etc. M as será também um caso em um sentido singular, no qual o adoecimento ou preocupação com a saúde de um indivíduo ganha contornos únicos no âmbito de sua biografia (o caso da sua saúde), tanto em termos das suas origens e determinantes como de suas implicações e significados (Gadamer, 1997). Para alcançarmos esse segundo sentido de um caso na atenção à saúde parece claro que precisamos incorporar o primeiro a uma abordagem que extrapola o estrito manejo biomédico - embora sem abrir mão dele mas, ao contrário, procurando também aprimorar sua qualidade. É a essa ampliação de horizontes, à necessidade de abordar de forma integrada os "casos" de saúde nos dois sentidos acima, que se refere o conceito de Cuidado (Ayres, 2004a; 2004b; 2004c), norte teórico-filosófico deste ensaio.

Entende-se aqui que a interven ção técnica se articula verdadeiramente como um Cuidar quando o sentido da intervenção passa a ser 
não apenas o estado de saúde visado de antemão, nem somente a aplicação mecânica das tecnologias disponíveis para al cançar este estado, mas o exame da relação entre finalidades e meios e seu sentido prático, conforme um diálogo o mais simétrico possível entre profissionais e usuários dos serviços (Ayres, 2004a).

À semelhança do que ocorre com a expressão "humanização da atenção", essa ativa incorporação de elementos práticos que transcendem o estrito recorte biomédico do adoecimento também tem merecido distintas leituras. Isto porque tais aspectos são tratados ora como um componente da atenção completamente distinto e externo à técnica, ora como uma questão de modulação, de mera adequação da técnica à diversidade de contextos de sua aplicação. Assim, de um modo ou de outro, essa dimensão da atenção, embora considerada importante, acaba por ter seu sucesso avaliado segundo o mesmo horizonte normativo de êxitos técnicos, acima apontados. Negligencia-se a consideração do sucesso da intervenção no que se refere ao horizonte pessoal e social que, como apontado, são inseparáveis da gênese dos processos de adoecimento e das motivações e significações que levam os indivíduos a demandar atenção à sua saúde (Ayres, 2004c).

No cotidiano da atenção à saúde, um dos grandes desafios é, portanto, pensar e operar essa dimensão prática que extrapola os objetos produzidos pelas tecnociências biomédicas, incorporando-a ativamente aos objetivos e meios do projeto assistencial, e fazendo sujeitos dessa incorporação tanto os profissionais quanto os usuários dos serviços.

Afinando-se com os pressupostos acima expostos e assumindo que a reconstrução do trabalho em saúde implica um ativo envolvimento da gestão dos serviços, entendida como um processo coletivo e interativo de construção e reconstrução de subjetividades, identidades e projetos da equipe (O nocko Campos, 2003), iniciou-se o processo de reflexão a ser sistematizado a seguir.

\section{Um serviço de HIV/Aids repensa suas práticas}

Desde a sua criação, em 1996, os serviços ambulatoriais especializados em DST/Aids do município de São Paulo, a partir de diretrizes dos Programas Nacional, Estadual e M unicipal, vêm discutindo e implementando propostas específicas para a atenção à saúde de pessoas vivendo com HIV/Aids, através de investimentos em capacitações, treinamentos e reciclagens dos seus profissionais.

Tais investimentos propiciaram não apenas o aprimoramento técnico no manejo das doenças sexualmente transmissíveis e da Aids, mas, sobretudo, melhorias no acolhimento ao usuário, entendido como uma ativa permeabilidade do serviço à ausculta e produção de algum tipo de resposta às diversas necessidades de cuidado trazidas pelo usuário (Franco et al., 1999); na agilidade no fluxo de atendimento; no envolvimento dos profissionais com o trabalho; na motivação para o aprimoramento científico.

Não obstante os evidentes ganhos destes investimentos, ainda permanecem al gumas lacunas nas práticas assistenciais, sobretudo aquelas não previstas em diretrizes, normatizações ou protocolos mais gerais de procedimentos, em um plano operatório do trabalho em saúde que M ehry (1997) chama de "tecnologias leves". N este plano operatório, presenciamos cotidianamente situações nas quais a busca do controle da doença colide com os projetos pessoais dos usuários, como nos problemas de adesão ao tratamento medicamentoso (Teixeira et al., 2000), no desejo de engravidar de muIheres e homens soropositivos (Paiva et al., 2003) ou na dificuldade de revelação do diagnóstico a crianças e adolescentes vivendo com HIV (M oreira \& Cunha, 2003).

Tome-se a questão da adesão, por exemplo. Os consensos de terapia anti-retroviral são claros quanto às situações clínicas e laboratoriais que indicam a necessidade de prescrever determinadas combinações de medicamentos, usando para isso critérios bastante objetivos, como contagem de linfócitos, magnitude da carga viral, condição clínica, etc. N ão há a mesma clareza, contudo, sobre os determinantes e manejos possíveis para os casos dos usuários que não queiram ou não consigam seguir tal prescrição - padrões de não adesão, possibilidades de compreensão desses padrões, possíveis alternativas para lidar com cada um desses diferentes padrões. A não adesão ao tratamento medicamentoso não é apenas um fracasso do ponto de vista clínico e epidemiológico. Ele significa também que no "caso da saúde" daquele indivíduo, no sentido da experiência singular do seu adoecimento, a não adesão pode estar respondendo a crenças, valores, condições específicas de vida que precisam ser ativamente exploradas para serem compreendidas. 
Foi a partir de desafios como os acima expostos que surgiu a proposta, na unidade de saúde a que se refere este estudo, da realização de uma série de encontros entre os profissionais da equipe, cuja pauta principal foi discutir a atenção prestada, especialmente na sua dimensão não padronizada, isto é, as ações não fixadas habitualmente em protocolos ou normas, referentes ao dia-a-dia do trabalho. Oscasos se sucedem no cotidiano dos serviços e, diante das suas singularidades, os profissionais vão achando, individual e empiricamente, soluções ad hoc para cada um. A proposta foi refletir um pouco sobre quais eram essas soluções que já estavam sendo dadas no dia-a-dia, com base em que princípios e procedimentos, e em que medida essas soluções podiam ser sistematizadas, compartilhadas e aprimoradas pelo e para o conjunto da equipe.

A unidade ambulatorial em questão localiza-se na região norte da cidade de São Paulo, tem uma média de 2.900 usuários matriculados e recebe diariamente cerca de 250 pessoas em atendimentos médicos, psicológicos, de assistência social, grupos, etc. Sua equipe é constituída por 70 membros, sendo nove médicos, cinco enfermeiros, dois psicólogos, cinco assistentes sociais e outros profissionais de nível técnico e administrativo.

Para o processo de discussão, foram promovidos quatro encontros na própria unidade, com intervalos de um mês e duração de três horas cada, no período de junho a setembro de 2004. Foram promovidos encontros distintos para os profissionais do turno matutino e vespertino, contando com a participação de 25 profissionais, em média, em cada um deles. Ao final dessa série de encontros, realizou-se um seminário, com a participação de 70 profissionais, dentre técnicos e administrativos. 0 seminário visou organizar e compreender, à luz do conceito de Cuidado, o conjunto de questionamentos e discussões levantados ao longo do processo.

Para orientar as discussões realizadas na unidade, a cada encontro propuseram-se alguns temas, discutidos em subgrupos, cujos produtos foram depois apresentados em plenárias. Temas propostos: avaliação da atenção; finalidades do serviço especializado; responsabilidades pelo tratamento e expectativas dos usuários em relação ao serviço. Os principais conteúdos das discussões realizadas nos grupos e no seminário foram organizados em três eixos, apresentados a seguir.

\section{Um olhar sobre a atenção}

\section{0 reconhecimento da humanização na atenção prestada}

Ao avaliarem a atenção oferecida aos usuários, os trabalhadores do SAE foram unânimes em reconhecêla como diferenciada, em comparação a outros serviços.

A pontou-se, nesse sentido, desde a preocupação com o ambiente físico da unidade, o oferecimento de lanche aos usuários, a disponibilidade de vagas para atendimento médico em casos de intercorrências, os agendamentos escalonados para diminuir o tempo de espera pelas consultas, até a explícita preocupação com uma atenção "humanizada", especialmente pelo estabelecimento de relações interpessoais atenciosas e afetivas entre profissionais e usuários.

Este último aspecto teve especial destaque, com relatos dos profissionais sobre usuários que afirmavam considerar este serviço a sua própria família, podendo-se dizer, então, que as relações interpessoais, centradas nos afetos, foram tomadas como um dos principais diferenciais da atenção. A perspectiva dominante, nesse sentido, foi de que o usuário é social, econômica e culturalmente menos favorecido e, portanto, al guém que deve ser "amparado" pelos profissionais de saúde.

Ocorreque se tal prática facilita, por um lado, o estabelecimento de vínculos, por outro, baseia-se numa certa informalidade, na dependência de juízos e vontades pessoais, sobretudo por parte dos profissionais. Esta atitude muitas vezes caracteriza uma relação de dependência, reiterando assimetrias entre usuários e profissionais, assi metrias tradicionais na cultura institucional dos serviços de saúde de modo geral.

\section{A centralidade do controle da doença}

Quando convidados a refletirem sobre as finalidades do trabalho desenvolvido, os profissionais, embora levantando inúmeras dimensões da atenção, tanto econômicas quanto sociais e subjetivas, privilegiaram nitidamente os aspectos relativos ao controle clínico da infecção, como era esperado.

Condições precárias de moradia, problemas com alimentação e dificuldade para transporte foram mencionados como obstáculos para o sucesso do controle da doença, finalidade da atenção. Diante dessas situações, foram evidenciados dois tipos de entendimento: ou esses 
aspectos eram apontados como limites do serviço de saúde, obrigando a circunscrever sua esfera de ação à doença, com formulações do tipo nós estamos resolvendo a parte técnica, que sabemos fazer, não conseguimos dar conta dos outros aspectos da vida do paciente; ou se apontava a necessidade incontornável de responder a essas demandas, para que um melhor resultado técnico pudesse ser obtido, com argumentações como é preciso conhecer a realidade do paciente e amenizar o seu sofrimento para o sucesso do tratamento, aqui não dá para ser mecânico.

Se alguns profissionais alertavam para o risco de imobilização da atenção diante de contextos sociais adversos, nos quais não se pode intervir diretamente, embora tenham impacto sobre o tratamento, outros apontavam a premência de tomar tais contextos como fundamentais na atenção, já que são inevitáveis e freqüentes as situações nas quais os profissionais e o serviço precisam suprir algumas carências dos usuários, seja às suas próprias expensas, seja abrindo regimes de exceção nas rotinas do serviço. Em ambas as perspectivas, ficou patente o obstáculo para o controle da doença oriundo das precárias condições sociais e econômicas dos usuários do serviço, diante das quais os profissionais polarizam entre o sentimento de impotência ou de completa responsabilização - o que nem sempre implica a inclusão dos próprios usuários na busca de soluções. A responsabilidade pelo tratamento pareceu muitas vezes restrita ao profissional, associada à sua maior capacidade e capacitação para tomar as decisões pertinentes, sendo somente "transferível" ao usuário alguns aspectos marginais, como pequenos ajustes nos horários das refeições, na freqüência de agendamentos, na medida em que estes correspondessem às expectativas dos técnicos.

\section{A autonomia do usuário: um outro sujeito no espaço assistencial?}

Considerando sua centralidade entre as finalidades da atenção, a adesão ao tratamento anti-retroviral foi tomada como situação privilegiada para debater o papel do usuário no projeto terapêutico.

Ao serem questionados explicitamente acerca da responsabilidade sobre a adesão, os profissionais de saúde tenderam a remetê-la a eles próprios e aos usuários (em alguns casos, aos seus familiares), mas, conforme acima apontado, freqüentemente como uma "del ega- ção", que pode ou não ser possível, a depender de algumas condições desses usuários. Essa percepção pode ser sintetizada em falas como: o problema é do paciente, desdeque ele tenha entendimento, mas se torna nosso também porque ele irá nos trazer mais problemas, caso venha a adoecer.

Para que o usuário possa assumir a responsabilidade pelo seu tratamento, pressupõe-se que ele deva ser informado e orientado adequadamente, de forma a, nas palavras dos profissionais, "se conscientizar" da importância de seguir suas prescrições. Para enfrentar a situação, as sugestões levantadas pelos profissionais durante as discussões transitaram entre a repetição maciça de informações esclarecendo, por exemplo, a importância da adesão ao medicamento e ao serviço, até a criação de equipes específicas com encargo de tratar dessa questão.

$M$ ais uma vez presencia-se a preocupação com aspectos relacionais da atenção, mas ainda como um "instrumento" para a finalidade de controle da doença. Além disso, percebe-se que, quando 0 acompanhamento do usuário foge dos scripts previstos pelos profissionais, estes não escondem sua frustração diante da situação, na qual, não raro, investiram muito, inclusive afetivamente.

Um caso exemplar diz respeito a um usuário que necessitava de uma cirurgia ocular, sem a qual o prognóstico seria a perda da visão em um dos olhos. Houve uma intensa mobilização da equipe para se conseguir uma referência hospitalar o mais rápido possível. Recorreu-se até a meios não formais para garantir a cirurgia. Contudo, para a profunda decepção de todos, ele não compareceu à cirurgia agendada, alegando que, na mesma data, tivera a oportunidade de realizar um trabalho cuja remuneração garantiria o pagamento de uma conta em atraso.

Os comentários que surgiram a partir dessa história dão pistas sobre as dificuldades de trânsito da atenção entre um certo "ideal" e um "possível", que considere outros horizontes além daquele estritamente biomédico. Ao compartiIharem unanimemente a opinião de que"o meIhor" para esse usuário teria sido a realização da cirurgia, considerando que ele acabou mesmo perdendo a visão no olho acometido, os profissionais de saúde interpretaram a situação como uma ruptura unilateral no projeto terapêutico, rotulando, de certo modo, o usuário como aquele que "não liga para a própria saúde".

Se houve, no início do processo, uma unanimidade de que havia uma qualidade diferen- 
ciada do serviço, atribuída, sobretudo, aos aspectos relacionais da atenção, indicando uma prática compromissada com o usuário, interessada na ampliação dos seus aspectos comunicacionais, então por que a efetiva incorporação da presença autônoma deste sujeito na atenção à saúde se torna às vezes tão difícil? Por que é tão difícil para a equipe assumir que as prioridades do usuário podem não coincidir inteiramente com as da equipe? Pode o usuário ser mais que objeto da interven ção? Pode ele, como sujeito de sua saúde, ter prioridades diversas daquelas dos profissionais?

O flagrar dos conflitos, ambigüidades e contradições experimentados pela equipe ao longo do processo de reexame do modelo de atenção da unidade foi oportunidade de aprendizado para a equipe, promovendo uma grande mobilização, inclusive de caráter afetivo. "N unca mais seremos os mesmos", disse um dos participantes ao final do seminário de encerramento do processo de discussão. A fala expressa, por um lado, a fecundidade do debate e das reflexões realizadas, mas, por outro, a extensão e profundidade das questões levantadas quando se trata do desafio da humanização. $\mathrm{N}$ esse sentido, vale concluir este artigo com uma breve reflexão filosófica suscitada pelo processo acima descrito e que se acredita poder trazer sugestões para a elaboração dos conflitos, ambigüidades e contradições levantadas.

\section{Compaixão, diálogo e os sujeitos do cuidado}

U ma das questões que se impuseram à reflexão a partir dos debates realizados na equipe foi a motivação, o impulso que leva os profissionais a, diante das dificuldades sociais e subjetivas dos usuários, adotar iniciativas pessoais para sua resolução. N esse sentido, vale um diálogo com o trabalho de Caponi (2000), que, ao analisar as motivações éticas que fundaram diversas modalidades historicamente observadas de assistência médica aos necessitados, demonstra que estiveram apoiadas na compaixão, ora como caridade, ora como utilitarismo filantrópico, ambos pressupondo, e recriando, relações de forte assimetria entre assistentes e assistidos.

Segundo essa autora, o grande desafio da relação estabelecida na base da compaixão é tomá-la como uma categoria moral ou social, "a ponto de nos construir como agentes morais ou quando pretendemos fundamentar nela uma ordem social justa" (Caponi, 2000). Lembra que a justiça só pode ser compreendida em conjunto com a eqüidade e a imparcialidade e que as diferenças que o compassi vo reforça dificilmente podem produzir relações fundadas na eqüidade, até pela simples razão de que a compaixão não tem por objetivo transformar as condições materiais que conduzem à desigualdade (Caponi, 2000). Mas será que éimpossível compatibilizar compaixão com simetria, com reconhecimento do lugar do usuário como sujeito? Vimos na discussão realizada pela equipe da unidade que a "com-paixão", o colocar-se no mesmo pathos, no mesmo caminho do usuário, foi um fator que mobilizou nos profissionais movimentos de acolhimento, vínculo, responsabilização, atitudes e ações altamente val orizadas pelas recentes proposições de humanização dos serviços. A questão, então, é como preservar esse potencial humanizador sem comprometer outro aspecto altamente desejável das propostas de humanização, que é a autonomia do usuário, sua condição de sujeito, relações simétricas entre profissionais-usuários.

Segundo Caponi (2000), o reconhecimento de simetria numa relação de compaixão é possível, mas apenas quando existe proximidade e identificação com a pessoa considerada desafortunada; apenas quando podemos reconhecer naquele que sofre um semelhante, alguém com 0 qual seja possível argumentar e discordar, formular perguntas e respostas, alguém, enfim, que possa preferir prescindir do nosso auxílio. A compaixão pode ser compatibilizada com simetria, em síntese, quando aquele com quem partilhamos o caminho for tomado como autêntico interlocutor e não apenas como um "objeto" de nossas iniciativas. A partir do reexame crítico da compaixão, pensamos que a avaliação da equipe sobre a atenção à saúde pode lograr um importante sal to de qualidade, na medida em que consiga colocar em relação o impulso compassivo - que, segundo a própria equipe, é uma marca sua - com o princípio de eqüidade (não igualdade, ressalte-se) entre profissionais eusuários - também um valor resguardado pela equipe.

Esta é uma tese a ser mais bem desenvolvida, refletida e discutida, certamente. Contudo, não é nova a idéia de que esses afetos que nos colocam em efetivo contato com as pessoas, fazendo-nos interessar por elas, não são elementos irracionais e que, como tais, devam ser recusados. Os afetos não são estranhos à razão, e, especialmente, não são incompatíveis com 0 
que esta possa vir a produzir de humano para os humanos. A filosofia de Espinosa (1991) talvez seja o melhor exemplo de elaboração sobre esta relação entre afeto e razão. Segundo sua Ética, os afetos positivos, que nos ligam a um outro sujeito, orientados pela idéia de Bem, são expressões imanentes de nossa própria condição humana e a possi bilidade mesma de organizarmos nossa existência de forma racional e justa. A poiando-nos numa filosofia da saúde de inspiração espinosana (Teixeira, 2004), podemos assumir que a compaixão só se tornará um afeto negativo para o encontro entre profissionais e usuários quando diminua suas potências, isto é, quando limite, naqueles ligados pelo afeto, sua capacidade de buscar aquilo de que necessitam, de se fazerem felizes. M as este se deixar afetar pelo outro pode ser uma oportunidade de aumento de potências de vida e de felicidade, tanto para o usuário do serviço como para o profissional, desde que a experiência proporcionada por esse encontro possa ajudar ambos a enriquecer sua percepção de quais movimentos práticos e técnicos são conveni entes para lidar com a situação de atenção demandada.

Essa potencialidade prática da compaixão, mediada pelo vínculo entre afeto e razão, nos remete a um outro quadro filosófico bastante diverso em suas origens, mas que também traz subsídios fundamentais para esta reflexão. Trata-se da perspectiva da ação/razão comunicativa de $\mathrm{H}$ abermas (1988).

Embora sendo quadros muito distintos, não nos parece um mau ecletismo sustentar que esses aportes filosóficos podem se complementar e enriquecer na aplicação à questão aqui tratada. Com efeito, o próprio Espinosa (1991) nos mostra que a passagem dos encontros no/pelo afeto para ações que nos são convenientes, se faz por meio de constructos racionais. É aqui que se torna possível e, em nossa opinião, desejável um diálogo com $\mathrm{H}$ abermas (1988). I sto porque, embora estranha ao panracionalismo imanentista de Espinosa, a concepção pragmática, construtivista e intersubjetivamente construída da razão em $\mathrm{H}$ abermas aproxima-se da idéia de razão como potencializadora da construção compartilhada da Boa Vida, e tem como corolário as mesmas recusas fundamentais do espinosismo: a opressão, a supressão da liberdade, o empobrecimento das potencialidades humanas. Em $\mathrm{H}$ abermas encontramos uma radical aposta na capacidade racional do diálogo de nos tornar todos, solidariamente, sujeitos de nossos destinos.
A necessidade de uma interação usuáriosprofissionais no sentido acima defendido aponta para o que Habermas (2004) considera 0 sentido forte de uma ação comunicativa lingüisticamente mediada. Ou seja, a busca de entendimento entre sujeitos que interagem simetricamente em diálogos que estendem suas pretensões de acordo até a esfera normativa, até um consenso racionalmente construído acerca do que seja ética e moralmente desejável pelos participantes do diálogo. Isso significa que o usuário do serviço precisa emergir no espaço assistencial de modo não restrito a elemento apenas coadjuvante da decisão do como fazer, mas que deve participar ativamente também das escolhas do que fazer.

Assim é que, ao buscarmos humanizar as práticas de saúde, parece-nos um ideal digno de ser perseguido e construído concretamente no cotidiano do trabalho em saúde essa aposta em um "diálogo aberto e produtivo entre a arte tecnocientífica do tratar e a construção livre e solidária de uma vida que se quer feliz" (Ayres, 2004b).

\section{Por um olhar desde a atenção}

A experiência aqui discutida mostrou que, ao responder à complexidade da tarefa de cuidar da saúde dos usuários movidos por um movimento individual de compaixão, colocado à margem do sentido técnico que atribuem ao trabalho, os profissionais ao mesmo tempo expressam e reproduzem as tensões de um modelo de atenção à saúde quase exclusivamente centrado no êxito técnico. Viu-se, por outro lado, que o problema central não é a preocupação com o êxito técnico, em si, mas o caráter monológico, unilateral, que suas finalidades e valores podem adquirir, obstaculizando a presença do usuário como um efetivo sujeito no cuidado da sua própria saúde.

Tais tensões tornam-se especialmente evidentes quando os problemas sociais ou as aspirações e val ores individuais dos usuários não coadunam com as medidas técnicas propostas, ou quando emergem dificuldades de relacionamento entre profissionais e usuários, ou entre os próprios profissionais, seja nas discussões formais, seja nas conversas informais.

0 simples tematizar dessas questões, tal como ocorreu na experiência aqui discutida, já abre caminhos para um diálogo mais efetivo entre os objetos e procedimentos próprios ao 
mundo das ciências e técnicas biomédicas e os significados que estas adquirem no viver cotidiano dos usuários. Esse diálogo, contudo, não éfácil, como se viu. A complexidade ea dificuldade da tarefa freqüentemente assustam, resultando em imobilismo ou sensação de impotência, sendo mais fácil a acomodação no já conhecido.

Nesse sentido, parece ser fundamental um continuado esforço, de equipes e usuários de serviços, gestores, representantes da sociedade civil e formuladores de políticas, de construção de espaços de efetiva comunicação, onde se possam relacionar objetivos técnicos com as finalidades mais amplas de sucesso prático de nossos usuários e populações. Assim, em que pese a importância de capacitações, treinamentos ou programas que visem a uma conscientização mais extensiva acerca da humanização das práticas de saúde, um resultado efetivo nesse sentido parece depender de questionamentos, debates, conflitos e consensos que podem ser tão melhor compreendidos e trabalhados quanto mais se basearem no fazer cotidiano dos serviços de saúde, nos afetos, diálogos e ações que se efetuam nesse rico espaço de encontros.

\section{Colaboradores}

LA Oliveira, M AS Landroni e NEK Silva participaram da concepção da intervenção e do estudo, da elaboração da reflexão sobre a experiência e da redação do artigo.

JRCM Ayres participou de parte das atividades de intervenção, da elaboração da reflexão sobre a experiência e da redação do artigo. 


\section{Referências bibliográficas}

Ayres JRCM 2001. Sujeito, intersubjetividade e práticas de saúde. Ciência e Saúde Coletiva 6(1):63-72.

Ayres JRCM 2004a. Cuidado e reconstrução das práticas de saúde. Interface: Comunicação, Saúde, Educação 8(14):73-91.

AyresJRCM 2004b. 0 cuidado, os modos de ser (do) humano e as práticas de saúde. Saúde e Sociedade 13(3): 16-29.

Ayres JRCM 2004c. N orma e formação: horizontes filosóficos para as práticas de avaliação no contexto da promoção da saúde. Ciência e Saúde Coletiva 9(3): 583-592.

Camargo Júnior KR 1994. As ciências da Aids e a Aids das ciências: discurso médico ea construção da Aids. Relume-Dumará, Rio de Janeiro.

Caponi S 2000. Da compaixão à solidariedade: uma genealogia da assistência médica. Fiocruz, Rio de Janeiro.

Deslandes SF 2004. Análise do discurso oficial sobre a humanização da assistência hospitalar. Ciência e Saúde Coletiva 9(1):7-14.

Espinosa B 1991. Ética - V, pp. 277-299. In M S Chaú́ (coord.). Espinosa. N ova Cultural, São Paulo (Coleção Os Pensadores).

Franco TB, Bueno WS \& M erhy EE 1999. O acolhimento e os processos de trabal ho em saúde: 0 caso de Betim, M inas Gerais, Brasil. Cadernos de Saúde Pública 15(2): 345-353.

Gadamer H G 1997. M istério da saúde, pp. 101-111. In HG Gadamer. 0 mistério da saúde: o cuidado da saúde e a arte da medicina. Edições 70, Lisboa.

H abermas J 1988. Teoría de la acción comunicativa. Editora Taurus, Madri.

H abermas J 2004. Verdade e justificação: ensaios filosóficos. Editora Loyola, São Paulo.

M artins M CFN 2003. H umanização da Assistência e formação do profissional de saúde. Psychiatry On-line Brasil (8). Disponível em <www.polbr.med.br/arqui vo/artigo0503_1.htm>Acesso em 17 de maio de 2005.

$M$ erhy EE 1997. Um ensaio sobre o médico e suas valises tecnológicas: contribuições para compreender as reestruturações produtivas do setor saúde. Interface: Comunicação, Saúde, Educação 6:109-116.
M inistério da Saúde - Programa Nacional de DST/Aids. 2004a. Recomendações para profilaxia da transmissão vertical do HIV e Terapia Anti-retroviral em gestantes. Ministério da Saúde, Brasília.

M inistério da Saúde - Programa N acional de DST/Aids 2004b. Recomendações para terapia anti-retroviral em adultos e adolescentes infectados pelo HIV. M inistério da Saúde, Braślia.

Ministério da Saúde - Programa Nacional de DST/Aids 2004c. Guia de tratamento clínico da infecção pelo HIV em crianças. M inistério da Saúde, Brasília.

M inistério da Saúde 2005. Política Nacional de Humanização. Disponível em <http://portal.saude.gov.br/ saude/area.cfm?id_area $=389>$. Acesso em 16 de maio de 2005.

M oreira M CN \& Cunha CC 2003. Repensando as práticas e dilemas no cotidiano de atenção à saúde de crianças e jovens vivendo com HIV/Aids. Divulgação em Saúde para Debate 29:73-92.

Nemes M IB 2001. Avaliação em saúde: questões para o Programa de DST/Aids no Brasil. Associação Brasileira Interdisciplinar de Aids (ABIA), Rio de Janeiro.

Nemes M IB et al. 1999. Avaliação da aderência ao tratamento por anti-retrovirais de usuários de ambulatórios do sistema público de assistência à Aids no Estado de São Paulo: visão geral dos resultados da pesquisa. Prática H ospitalar 1(6):15-17.

Onocko Campos R 2003. 0 planejamento no labirinto: uma viagem hermenêutica. Hucitec, São Paulo.

Paiva VSF, Segurado A, Felipe EV, Santos N \& Lima TN 2003. The right to love: the desire for parenthood among men living with HIV. Reproductive $\mathrm{H}$ ealth M atters J ournal 11(22):91-100.

Schraiber LB 1997. No encontro da técnica com a ética: o exercício de julgar e decidir no cotidiano do trabalho em medicina. Interface: Comunicação, Saúde, Educação 1(1):123-138.

Teixeira RR 2004. A grande saúde: uma introdução à medicina do corpo sem órgãos. Interface: Comunicação, Saúde, Educação 8(14):35-72.

Teixeira PR, Paiva V \& Shimma E (orgs.) 2000. Tá difícil de engolir? N epAids, São Paulo.

Artigo apresentado em 18/04/05

Aprovado em 6/05/2005

Versão final apresentada em 17/05/2005 